\title{
Micro assessing Library impact story logs
}

$\mathbf{L}_{\mathrm{in}}^{\mathrm{ik}}$ ike many academic libraries, Princeton Theological Seminary Library's assessment activities have evolved over the last few years, and both broadened and deepened our understanding of our patrons; our collections, services, resources, and space; and ourselves as information professionals. The library is fairly practiced now at experimenting with and implementing a wide variety of qualitative and quantitative data gathering methodologies and tools to meet particular information needs or to answer specific questions.

However, even with a wide range of data gathering and feedback mechanisms, we realized that we were still missing somethingwe were missing the stories that lie in the gaps between the data sets, the narratives that tie various bits of data together. We needed a way to better capture patron comments, phone calls, emails, and passing conversations about library performance and impact because they can contain rich detail, specific use cases, and practical direct feedback.

These stories, often communicated in passing on the library floor or other campus spaces, are often only held anecdotally in the memory of the library staff involved, speed by in email or social media exchanges, or lie nestled in the conversations between patrons themselves-and thus can easily be lost or undiscovered in wider library assessment considerations because they are never gathered together. We decided to keep a better record of patron testimony about how the library could improve or how the library is making a difference in the work, scholarly, and (because we are a theological library) spiritual lives of our patrons. So we developed "Library Impact Story Logs." Each area of the library now has its own Impact Story Log-simple, quick, and shareable online documents that serve as holding tanks for the stories library staff accumulate while going about their day and through interactions with patrons.

Simple, quick, and shareable are key. We are using simple online documents, with minimal formatting requirements and basic instructions for the library staff that allow for rapid, on the go input.

Instructions at the top of each log remind staff of our aim:

How to use this story log: These Impact Story Logs will serve as a central place to collect stories that library staff may receive anecdotally via conversation, email, phone, etc. about how the library and its resources, tools, space, or people are directly impacting their life, scholarship, teaching, or preaching. To better record and track these individual stories, please update your Impact Story Log whenever you receive feedback or at some regular interval.

Jenifer Gundry is librarian for applications and assessment at Princeton Theological Seminary Library, email: jenifer. gundry@ptsem.edu

c) 2015 Jenifer Gundry 
The process is simple-make a note of the month/year and enter a brief summary of the impact you wish to note in a few lines. Feel free to copy and paste emails or other items into the log.

Stories can be comprised of almost anything: most common is a date reference and a short note, such as, "August 2014: M.Div. student used the video editing equipment in the Digital Scholarship Center to document her summer field education experience at a church in Ghana." But the logs are meant to be flexible, and any kind of input is welcome-most important to us is getting the testimony recorded. In addition to short, typed entries, story logs also contain items such as scans of handwritten notes, screenshots of social media interactions, and copy and pasted emails.

The bare bones format of the log's template was designed with an eye towards ease and speedy input. The whole process, from $\log$ in to input to saving, takes less than five minutes. Different areas of the library update their logs on different schedules, appropriate to their workflows, and this variety is expected and embraced: some departments input immediately after each interaction, some departments input weekly, some monthly. One area of the library submits quarterly narrative summaries to their log. All of it works.

Following implementation, one of our initial discoveries was the physical similarity of the log entries across departments of the library, from Special Collections to Digital Initiatives: most of the entries, composed quickly on the fly in two to four lines of text, physically looked like Tweets. We realized then that we were "micro-assessing." But this micro effort has proven to be important for our macro work.

\section{Four ways story logs have been useful}

First, the logs have helped the library contextualize the results of other data collection and impact assessment work by providing a growing list of real-life patron experiences, projects, and outcomes. These logs flesh out the data, making the numbers real, and create connections between occasionally disparate data sets and outcomes numbers.

We knew that our graduating students often made self-recordings of sermons, speeches, and other presentations to be output to YouTube or other various media to be included in their employment application packets. The logs helped us see how often this was happening, and motivated the library to plan to add a presentation-style lectern and portable backdrop to our audio/video editing rooms to further enhance their self-recording for this kind of work. Similarly, we could see from gate count numbers and other quantitative mechanisms that our patrons heavily use our new library building since its opening last year, but coupling those numbers with corralled comments about the building on social media and via email by our students, faculty, and alums over the first year of the building's use provided much more context in our understanding of the building's reception and use.

Second, the logs are a helpful resource to library administrators as they communicate the library's work and impact to other campus administrators and institutional stakeholders in reports and presentations. Stories do this work well, particularly for audiences not knee deep in assessment-speak or even libraryspeak. The reporting of hard numbers data will always be an important and necessary feature of communicating library use and impact to executive committees, boards of trustees, accrediting organizations, and other oversight bodies. In many cases, these groups may be comprised of individuals prized for their leadership and vision but who may not have extensive background in academic librarianship, library management, or indeed, even a detailed awareness of the complex and rapidly changing vagaries of the wider information, publishing, and scholarly communication landscape that we work in.

Real life stories taken from the Impact Story Logs can help make meaning of the statistics in important ways, pointing to how industry or national trends are being felt lo- 
cally, how a new resource or piece of equipment can impact patron productivity, or even how shifts in library organization might need to be considered going forward.

Though the logs are always visible to the library director, we make a point of packaging particularly interesting and informative stories from the logs for the library director in advance of important reporting deadlines and meetings of the trustees or alums, just so he has a ready-aid resource of recent cases easily at hand to share in formal or informal conversations with these important groups.

Third, by creating the story logs as shareable, viewable documents by all areas of the library, the library staff itself is more informed about the work and effectiveness of other departments and has a better understanding of the organization as a whole. Each area's Impact Story Log is viewable by all members of the library staff through the institution's file-sharing system Filr. (Other file sharing systems such as Google Docs, modified kanban boards, or various storyboarding tools could work, as well.) Library staff are thus not only better informed about what other departments are doing, but they also have a new lens on what interdepartmental connections might be possible.

For example, the story logs revealed the number of "on the fly" reference outreach interactions by our information services librarian as she managed our social media accounts: a student unaffiliated with our institution posted a general Tweet about his need for more information on Princeton Seminary, and our librarian replied with a title recommendation. Similarly, a seminary student Tweeted a general call for help on a book about baptism, and our librarian directed him to appropriate $\mathrm{BV}$ call numbers for baptism on our library's second floor. Both tiny and quite average exchanges in the world of library social media engagement, but without extracting them into the story logs, many of the other areas of the library would have missed both this outreach effort and, perhaps most importantly, the subject areas of expressed patron interest, which their departments may want to keep a finger on.

The very fine work of our Special Collections is testified to by the range of activities and topics in their logs. In one brief period, the small team hosted an impressive number of tours, illustrated talks, special exhibits, as well as visiting researchers from around the world-New Zealand, Hungary, Finland, Japan, and Canada.

As with the social media exchanges, the Special Collections log helps the rest of the library staff stay up to date on their activities and researchers' topics of interest. Additionally, the objectiveness of patron perspectives on what is useful, what can be improved, and what is needed in the library provide the staff with a neutral, exploratory conversational space in which to ask questions or propose changes based on patron stories.

Finally, and perhaps most importantly, the story logs have provided us with an additional lens on the scope and scale of our patron's scholarly activities. We know the "regular" library activities of many of our patrons because we see them in the building and, being a smaller institution, know the majority of our students and faculty personally: researching for course work, teaching, publishing, presenting, preaching, and personal growth. From the logs, we are regularly reminded of the variety of the patron experience.

One story from the logs alerted us to an important potential future archival donation: one alumnus used the scanning equipment in the Digital Scholarship Center to scan a cache of historic letters that he intends to donate to the seminary archives at some future date. Another story from the logs recounts the email of a remote researcher who wrote to thank the library for the Theological Commons ${ }^{1}$ (a freely available digital library in religion and theology), of which he made extensive use in preparing his forthcoming book with a major scholarly publisher. Capturing this kind of feedback has the added benefit of allowing the library to learn information about patron types who are more difficult to assess, such as alums, visiting and temporary researchers,

(continues on page 322) 
exists a "statistically significant" link between attention deficit and lower academic performance with time spent on social networking sites in "Effect of online social networking on student academic performance," Computers in Human Behavior 28 (2012): 2117-2127. See also M. Prensky, Brain Gain: Technology and the Quest for Digital Wisdom (Palgrave Macmillan: New York, 2012).

3. K. L. Wolever et al., "Effective and viable mind-body stress reduction in the workplace: A randomized controlled trial," Journal of Occupational Health Psychology, 17.2 (2012): 246-58.

4. B. Michels, D. Maxwell, and C-W. Chang, "Labyrinths: Yesterday, Today and TomorrowImplications for Education," Critical Questions in Education, 1:1 (2011): 26-39.
5. M. Shindle, "Walking the Labyrinth: An exercise in self-healing," American Nurse Today 3.8 (2008): 28-29.

6. J. Rhodes, "Commonly Reported Effects of Labyrinth Walking," Labyrinth Pathways (2008).

7. M. Zucker, "Labyrinth Walking in Corrections," Journal of Addictions Nursing 23 (2012): 47-54. Available at: http://works. bepress.com/donna_zucker/19.

8. P. Grossman, L. Neimann, S. Schmidt, and $\mathrm{H}$. Walach, "Mindfulness-based stress reduction and health benefits: A meta analysis," Journal of Psychosomatic Research 57 (2004): 35-43; see also K. Baicker, D. Cutler, and Z. Song, "Workplace wellness programs can generate savings," Health Affairs 29.2 (2010): 304-11. $\boldsymbol{n}$
"Micro assessing" (cont. from page 304)

and even remote researchers-patron groups that often fall outside of traditional feedback and assessment data collection mechanisms, patron groups that we may never see or know about beyond as a blip in our web analytics. The concreteness of the individual stories in the logs helps the library stay attuned to the variety of patron activity and to plan services and resources creatively.
Library Impact Story Logs. Simple idea. Big return.

\section{Note}

1. "Theological Commons," Princeton Theological Seminary Library, accessed September 10, 2014, http://commons.ptsem. edu. $\boldsymbol{n}$

"Past overdue!" (cont. from page 316)

\section{Opposition}

- Family Research Council (FRC). FightENDA.org is a campaign of FRC Action. This arm of the FRC, formed in 1992, was formed to educate society on the "traditional American values." Though the website has not been updated since 1993, it outlines the reasoning behind their opposition to employment protections for LGBT Americans. Access: http://www.fightenda.org/.

- The Heritage Foundation. This think tank, created in 1973 promotes conservative public policies. This page outlines the danger of providing workplace protections under ENDA and proposes that increased employment protections would weaken the First Amendment, lead to same-sex marriage, and threaten businesses. Access: http://www. heritage.org/research/reports/2013/11/endathreatens-fundamental-civil-liberties.

\section{Notes}

1. http://www.americanprogress.org/issues/lgbt/report/2013/06/04/65133/a-broken -bargain/.

2. http://www.advocate.com/employment -discrimination/2014/05/08/study -majority-lgbt-workers-closeted-job.

3. https://www.whitehouse.gov /blog/2015/04/08/another-step-toward -equality-lgbt-workers.

4. http://www.nytimes.com/2014/12/05 /us/advocates-seek-civil-rights-bill-for -lesbian-gay-bisexual-and-transgender -americans.html. $\mathbf{n}$ 